\title{
Crystallographic technology as the way of verification quality of solutions of high dilution
}

\author{
Olga Zhdanovaㄹ, Andrey Martusevich², NadezhdaMazina ${ }^{1}$, \\ Fernando Artese $^{3}$, Micele Troiano ${ }^{4}$, Olga Chasovskih ${ }^{5}$
}

\author{
${ }^{1}$ Kirov state medical academy, Kirov, Russian Federation \\ 2 Nizhny Novgorod Research Inst. of Traumatology and Orthopaedics, Russian Federation \\ 3 Director "Dental-center", Italy \\ ${ }^{4}$ Amega-group, Italy \\ 5 Kirov State Agricultural AcademyKirov, Russian Federation
}

Introduction: Studying of features of various influences on biosubstrates is interesting to practice, especially in the field of high dilutions (HD) researches. Majority of work in this area include only different methods of spectrophotometry, but informative approaches to their estimation are usually ignored, in particular, a crystallographic analysis is one of them. The present work is aimed at revealing thorough knowledge in the different influences'. The attempts of the crystallogenesis phenomenon are used in pharmacology of 30s years of XX century. At that time the priority problem, in these field, was shown the identification of preparations composition that was founded on suggestion about special type of their crystals. Besides, crystallographic analysis can be useful as way of verification quality. At present the growth of assortment and efficiency of influences' can be ranked to most significant trends of HD. As a rule, medical biological activity decreasing is accompanied by the parallel growing of electromagnetic, amega and another influence. This fact requires undertaking the careful test of proposed preparation for revision of all sides of its actions, for what the different biological models, first of all laboratory bestial, are often used. Methods: As analyzed samples of $\mathrm{NaCl}$ solutions were taken. The concentration at the solution was $0,1 \% ; 0,9 \%$ and $10 \%$ with the use of solutions of High Dilution of Arnica 6 before and after influence. We used some crystalloscopic methods of biofluids study, such as classical crystalloscopy, allowing install the particularities own crystallogenesis of biosubstrates, and differential teziography, visualizing biofluid initiation potential. Tezigraphic component was investigated by main and additional parameters, characterizing physical and chemical properties of biological fluids. The count of derived factors of the teziocrystalloscopy was realized for full mathematical description and modeling of biosubstratescrystallogenesis. The dehydration picture of solution of any component composition is resulting from multiple parameters. Statistical processing was executed in Microsoft Excel 2003 and program packages SPSS 11.0 and Primer of biostatistics 4.03. The NaCltesigrafic activity was compared with its crystalloscopy before and after influence (the estimation in vitro). Results: It was allowed to select the optimum concentration of $\mathrm{Na} \mathrm{Cl}$ solutions, which had sufficient activity $(0,9 \%$ solution). In this connection investigation in vivo (on laboratory mice) was continued with $0,9 \%$ concentration only. It is stated that the clear dependency exists between exercised concentrations of solution and crystalloscopic picture, formed by them. In particular, it is revealed that most typical crystalline form (the morphotype) for investigated join is single-crystalline structure of "pyramid" type. The information about facets, formed after influence, can be used for identification of facility with provision for its solution concentration.

Keywords: experiments, crystallogenesis phenomenon, biosubstrat 


\section{References:}

Martusevich A. K., Safarova R. I. Teziocrystalloscopic monitoring of the adaptation level in people with different sport efficiency. International symposium «Biological motility: basic research and practice». Pushchino. 2006; 126-128.

Lanzalaco A. C., Singh R. P., Senesco S. A. The influence of urinary macromolecules on calcium oxalate monohydrated crystal growth. J. Urol. 1988; 139(1): 190-195.

Shabalin V. N., Shatokhina S. N., Yakovlev S. A. Character of blood crystallization as an integral index of organism homeostasis. Phys. Chem. Biol. Med. 1995; 2(1):6-9.

\section{(c)) BY-NC-ND Licensed to GIRI}

Support: authors declare that this study received no funding

Conflict of interest: authors declare there is no conflict of interest

Received: April 1 $1^{\text {st }} 2014$; Revised:May 10th 2014; Published: June 30 2014.

Correspondence author: Olga Zhdanova, oliabio@yandex.rus www.kirovgmalinks.

How to cite this article: Zhdanova O, Martusevich A,Mazina N. , Artese F, Troiano M, Chasovskih O.Crystallographic technology as the way of verification quality of solutions of high dilution. Int J High Dilution Res [online]. 2014 [cited YYYY Month dd]; 13(47):141-142. Proceedings of the XXVIII GIRI Symposium; 2014 June 20-22; Sighisoara (Romania). GIRI; 2014; Available from: http://www.feg.unesp.br/ ojs/index.php/ijhdr/article/view/747/721 